Article

\title{
Barriers and Facilitators to Research Use Among Allied Health Practitioners: A Mixed- Method Approach to Assessment
}

\author{
Mary Dunne \\ Information Officer \\ National Documentation Centre on Drug Use \\ Health Information \& Evidence Directorate \\ Health Research Board \\ Dublin, Ireland \\ Email: mdunne@hrb.ie
}

Received: 20 Sept. 2011

Accepted: 13 Nov. 2011

(a) 2011 Dunne. This is an Open Access article distributed under the terms of the Creative Commons-AttributionNoncommercial-Share Alike License 2.5 Canada (http://creativecommons.org/licenses/by-nc-sa/2.5/ca/), which permits unrestricted use, distribution, and reproduction in any medium, provided the original work is properly attributed, not used for commercial purposes, and, if transformed, the resulting work is redistributed under the same or similar license to this one.

\begin{abstract}
Objectives - The disparity between what is known to be effective and what is done in practice points to barriers to research use among health practitioners. Library and information services (LIS) collect, organize and disseminate published research findings so they may be uniquely positioned to be of influence. This study aimed to identify barriers and facilitators to research use among allied health practitioners working in the alcohol and other drugs (AOD) field in Ireland, and to explore the services, strategies, and resources that may help alleviate these issues.

Methods - Three focus groups were held with AOD practitioners. A survey questionnaire was then sent by post to 175 counsellors. The survey included the Barriers to Research Utilization Scale (Barriers Scale) (Funk et al. 1991), which assessed potential barriers from four factors: practitioner, setting, qualities of the research, and communication.
\end{abstract}

Results - The number of responses was 71 (41\%). All communication-related Barriers Scale items, and some items associated with the setting and practitioner, were perceived to be a moderate or great barrier by the majority of survey respondents. Similar issues were also raised in focus groups, where language, presentation, and time to engage with research were considered significant influences. Qualitative aspects of the study also revealed scepticism about research application and relevance. 
All proposed LIS were rated as moderate or great facilitators by the majority of respondents who expressed an opinion (those who choose "no opinion" or did not respond, 6-8\%, were excluded).

Conclusions - The high incidence of communication-related issues among top barriers and the enthusiasm expressed about proposed library services and training reveals the key role that LIS personnel can play in enabling practitioners to use research in practice. The addition of setting and practitioner factors indicates that a holistic, collaborative approach to promoting the effective use of research collections and resources is required. Mixed-method data collection (focus group and survey) provided a rich source of information, and may offer a useful approach for future study.

\section{Introduction}

"Librarianship has had a long preoccupation with the research-practice gap" (Booth, 2003, p.3). Not only must LIS be informed by evidence, there is interest in how the research supplied to clients impacts on practice (and subsequent client/patient care) (Marshall, 2007).

The difference between what is known to be effective and what is done in practice points to barriers to research use among frontline practitioners (Hutchinson \& Johnston, 2006). Most studies examining this gap have involved health and medical professionals. Less is known about the needs of allied health practitioners, such as outreach, community, and project workers; counsellors; and education officers. Workers in the AOD area exemplify this grouping.

This study aimed to identify barriers to using research experienced by allied health practitioners working in the AOD area in Ireland, and to explore the information services, strategies and resources that might facilitate better use.

\section{Literature Review}

Most modern conceptions of evidence based practice recognise the importance of integrating knowledge from "scientific" research sources with knowledge from practice experience, colleagues, training, organisational policies, and clients (Eccles,
2009; Walter, Nutley, Percy-Smith, McNeish, \& Frost, 2004). That is, balancing explicit science with the tacit "art" of practice (Gioia, 2007).

Similarly, there are many ways in which research evidence is used. Research use not only applies where there is a direct impact on decision making (instrumental use), it also includes raising awareness of research findings, changing attitudes and beliefs, increasing knowledge and understanding (conceptual use), and justifying a position, action, or inaction (symbolic use) (Arney, Bromfield, Lewig, \& Holzer, 2009).

\section{Diffusion and Research Use Theory}

The transfer of research into practice is a complex process, though there have been recent attempts to define relevant concepts (Addiction Technology Transfer Center Network Technology Transfer Workgroup, 2011).

There appears to be some consensus that there is no "one size fits all" approach to effective research transfer, and that numerous interactive factors must be considered, such as the setting, the individual, the communication channels, and the evidence itself (Eccles, 2009; Greenhalgh, Robert, Macfarlane, Bate, \& Kyriakidou, 2004).

Theories, models, and frameworks in this field range from those that focus on individuals (intrapersonal and interpersonal change) to 
those that explain or predict action at higher levels (ecological/organisational change) (Bywood, Lunnay, \& Roche, 2008b). These may guide LIS personnel when selecting types of assessment tools and interventions.

For example, the PARIHS (Promoting Action on Research Implementation in Health Services) framework reveals the interdependent relationship between the nature of the evidence, the context, and the facilitation method (Kitson et al., 2008). And the TCU (Texas Christian University) programme change model developed in the AOD field, outlines the factors that might affect the transfer of research into practice (Simpson \& Flynn, 2007). Both of these emphasize careful diagnosis and planning within client contexts, and underpin useful assessment tools (Bartholomew, Joe, RowanSzal, \& Simpson, 2007; Helfrich, Li, Sharp, \& Sales, 2009; McCormack, McCarthy, Wrigh,t \& Coffey, 2009).

Rogers's Diffusion of Innovations (1962; 2003) theory has also influenced much study of the research-practice gap. In an extensive review, Bywood et al. (2008b) placed this multidimensional, behavioural, stage theory among 20 theories that appeared to have the greatest potential for use in dissemination and implementation of innovations in the AOD area.

However, Diffusion of Innovations has been subject to criticism. For example, it does not address self-efficacy (people's beliefs about their performance capabilities, which determine how they feel, think, motivate themselves, and behave (Bandura, 1994)), and the need to develop change skills (Bywood et al., 2008b). The theory has also been faulted for appearing to divide the population into progressive insiders (innovators) and stagnant outsiders (imitators or "laggards") (McMaster $\&$ Wastell, 2005). This theory must therefore be applied with care, with practitioners as partners rather than "recipients" of knowledge. Despite these reservations, the theory appears to be a sound basis from which to explore research use in practice.

\section{Assessment Tools}

There are at least 25 instruments designed to measure nurses' attitudes towards research utilisation (Frasure, 2008). This proliferation of instruments demonstrates the difficulty in choosing methods that can capture the multiple factors that influence research use in practice. In a review of studies examining barriers and integration of evidence into practice between 1998 and 2007, Cochrane and colleagues remarked on how few surveys were based on existing theoretical frameworks, though stated that "the exception is the comprehensive barrier assessment, BARRIERS" (2007, p.97).

Based on the theory of Diffusion of Innovations, the Barriers to Research Utilization Scale tool was devised by Funk, Champagne, Wiese, and Tornquist (1991) to examine the barriers and facilitators to using research in nursing practice (http://barriers.web.unc.edu/). The Barriers Scale has been used extensively in the US, Australia, the UK, and other European countries. A 2010 review by Kajermo et al. included 65 studies using the Barriers Scale. It forms a large part of the questionnaire used in the present study.

The Barriers Scale has been described as the most frequently used method to determine barriers in research use (Hutchinson \& Johnston, 2004). It comprises 29 items related to four factors: the practitioner, the setting, qualities of research, and communication. Reliability tests have shown that the items fit well within these factors (Funk et al., 1991; Yava et al., 2009), though other factor solutions have been proposed (Closs \& Bryar, 2001; Retsas, 2000). The Barriers Scale survey also provides an opportunity for respondents to add barriers and suggest up to three facilitators of research use.

In this study the first person pronoun ("I") and terms more familiar to Irish workers were used. Similar modifications have been made in previous studies (Kajermo et al., 2010), however no assessment of the effect to validity was made in this case. 
The Barriers Scale has been criticised for ignoring wider environmental, political, and technical factors, and not always translating well to European contexts (Boström, Kagermo, Nordström, \& Wallin, 2008; Closs \& Bryar, 2001). However the Barriers Scale has been used in numerous countries around the world, including Ireland (Glacken \& Chaney, 2004; Parahoo, 2000). It includes multiple factors, and the content and face validity have been widely tested and supported (Hutchinson \& Johnston, 2006). Although titles may differ, similar factors have also been found using other assessment tools, for example, the PARIHS-based ORCA survey (Helfrich et al., 2009).

\section{Facilitators of Research Use}

Successful implementation of research is affected by the type of evidence, the qualities of the context and the way the process is facilitated (Kitson et al., 2008). Examining all of these elements is therefore important.

The most successful implementation strategies address change at multiple levels and are sustainable over a prolonged period (Bywood, Lunnay, \& Roche, 2008a). They also include particular features (Table 1).

Table 1

Features of Successful Implementation Strategies and Related Factors

\begin{tabular}{|c|c|c|}
\hline $\begin{array}{l}\text { Strategies for overcoming } \\
\text { barriers }^{\mathrm{a}}\end{array}$ & Features of successful strategies ${ }^{b}$ & $\begin{array}{l}\text { Corresponding } \\
\text { Barriers Scale } \\
\text { factors }\end{array}$ \\
\hline $\begin{array}{l}\text { - Address factors relating to the } \\
\text { individual } \\
\text { - Build relationships between } \\
\text { researchers, practitioners and } \\
\text { policymakers }\end{array}$ & - Assessment of, and focus on, barriers to change & Practitioner \\
\hline $\begin{array}{l}\text { - Understand and accommodate } \\
\text { the influence of environmental } \\
\text { context }\end{array}$ & $\begin{array}{l}\text { - Organisational changes that require practitioners to } \\
\text { respond or take action } \\
\text { - Clear identification of roles and activities }\end{array}$ & Setting \\
\hline $\begin{array}{l}\text { - Address the nature of research } \\
\text { evidence and build agreement } \\
\text { around evidence }\end{array}$ & $\begin{array}{l}\text { - Reliable and credible source, with accurate, evidence } \\
\text { based information }\end{array}$ & Research \\
\hline $\begin{array}{l}\text { - Improve the presentation and } \\
\text { dissemination of research } \\
\text { findings }\end{array}$ & $\begin{array}{l}\text { - Tailored information that is personalised and modified } \\
\text { to the local setting } \\
\text { - Information relevant to the practitioner and their client } \\
\text { needs } \\
\text { - Clear and succinct message, with simple, focused } \\
\text { objectives that require small practical changes } \\
\text { - Interactive format that is appealing, persuasive and } \\
\text { encourages participation } \\
\text { - Reinforced messages, with additional materials and } \\
\text { support } \\
\text { - Systems or procedures that are accessible and easy to } \\
\text { use, with little effort required to comply }\end{array}$ & Communication \\
\hline
\end{tabular}

a Lewig, Arney \& Scott, 2006; b Bywood et al., 2008a; c Funk et al., 1991 


\section{Methods}

Cochrane and colleagues' (2007) review of 256 journal articles examining barriers and integration of evidence into practice, found that surveys were the most popular measure (70\% of studies), but that use of qualitative (focus groups (6\%); interviews (7\%)) and mixed-method approaches (17\%) was increasing.

The three methods of data collection used in this study gave comprehensive and complementary information. The literature review provided context and guidance. The qualitative, focus group aspect allowed participants to raise their own issues in an open forum. The quantitative, survey approach then facilitated taking these themes to a larger population; enabled (some) comparison with other studies; and will facilitate future replication.

\section{Focus Groups}

Three focus groups were conducted with students from an addiction studies course during a day-long visit to the National Documentation Centre on Drug Use in Dublin (http://www.drugsandalcohol.ie). Students were randomly assigned in groups of six or seven to sessions lasting an average of 40 minutes. The students' occupations and backgrounds mirrored the diversity found in AOD practice.

The schedule was guided by existing research (Callaghan, Doherty, Lea, \& Webster, 2008), and began with an introduction followed by an opening question (about research information sources) designed to promote thinking around research use. To encourage open dialogue, just two core questions (about experiences of barriers and facilitators) were asked. A round-up and brief summary were made in conclusion.

All issues raised in the focus groups could be aligned with the four Barriers Scale factors, underlining the Barriers Scale's suitability as a measurement tool.
Survey

Following a pilot study, and some adjustments to language and length, a survey questionnaire was sent to all 175 counsellors who provided alcohol, drug, or addiction counselling listed in a national online directory (32 organisations and 143 individual counsellors).

The questionnaire was sent by post with an explanatory cover letter and freepost return envelope. No personal details were obtained. Reminders and letters of thanks were sent ten days later. Completion and return was taken as implied consent to use the data, which was collected over a five week period.

The questionnaire had four sections: demographic profiles, current research use and potentially associated variables, potential library service facilitators, and the Barriers Scale. A final open-ended question invited comments.

\section{Results}

Response Rate

The response rate for this survey was $41 \%$ (71 responses from 175). This low rate, although consistent with other Barriers Scale studies, may suggest response bias (those most concerned with the subject are the most likely to respond). Although the low response means that generalisations cannot be easily made, there were a sufficient number of respondents to indicate the challenges faced by the survey population in using research.

\section{Survey Respondent Variables}

There was a good mix of rural (40\%) and urban-based (60\%) respondents. A high percentage of survey respondents have thirdlevel qualifications (83\%), and are currently engaged in study (24\%). A larger study would be able to assess whether these and other variables are correlated with barriers and facilitators of research use. 
Leadership support has been found to be an important facilitator of research use (Yava et al., 2009). Of the survey respondents who had managers $(n=39)$, the majority were positive about the support they received from their managers in finding evidence (59\%) or engaging in training courses $(64 \%)$ during work hours. Most respondents (76\%) had access to the Internet at work, which suggests this is a useful medium for practitioners to access the AOD literature.

More than half searched for evidence from published research sources at work at least once a week/month (59\%). An even higher percentage searched for evidence from home (70\%). Only one respondent never searched for AOD research. These responses suggest an active and motivated group of $\mathrm{AOD}$ practitioners that requires access to resources at various times and locations, including outside of office hours.

Although numbers were small, some tests of association between variables were performed, for example, between level of management support and frequency of searching; between type of setting (rural and urban) and how frequently new research is discussed with colleagues/peers; and between level of qualification and frequency of searching for evidence. There was just one statistically significant relationship. Higher qualifications were associated with more frequent searching for evidence at home $(\mathrm{p}=0.001)$.

\section{Barriers Scale}

The focus group discussions were not intended to provide a representative list of barriers, but rather a general impression of what influenced participants' use of published research. Emerging themes were compared against the four factors of the Barriers Scale. Analysis showed that key themes were repeated in each session.

Survey respondents scored each Barriers Scale item from 1 (not a barrier) to 4 (a great barrier). There was also a "no opinion" option.
The average score across all items was 2.37. The top 13 items were rated as a moderate or great barrier by the majority of respondents who expressed an opinion (Table 2).

Twelve survey respondents added items that they perceived as barriers. Some of these related to existing Barriers Scale items (lack of time, not user friendly, poor presentation, too complex) or emphasized unease with the type of research being produced:

Research results often tend to dehumanize the client. (Survey Respondent 4)

$$
\begin{aligned}
& \text { Not focused enough on 'social } \\
& \text { psychology' of addictions. (Survey } \\
& \text { Respondent 5) }
\end{aligned}
$$

Barriers that could not be easily associated with existing items related to lack of information sharing across groups or organisations, funding constraints, and cultural differences when integrating research into practice.

\section{Characteristics of the Communication}

In this study, issues associated with communication were seen as the most significant barriers to research use. For focus group participants, issues of presentation and language were highlighted in all sessions. Many practitioners had no training in statistical analysis or were unfamiliar with the scientific terminology used in articles related to practice. This made relevant publications incomprehensible.

The language is very important. If the language looks like it's too technical then it's not as useful as if it's easy to understand. (Participant 2, Group 1)

Issues of clarity, language, and relevance were considered among the greatest barriers to research use by survey respondents also. Of note, seven of the top eight barriers related to research communication. 
Table 2

Mean Score for Barriers Scale Items

\begin{tabular}{|c|c|c|c|c|c|c|}
\hline & & $\begin{array}{l}\text { Commun- } \\
\text { ication }\end{array}$ & Setting & Research & $\begin{array}{l}\text { Prac- } \\
\text { titioner }\end{array}$ & $\begin{array}{l}\text { Moderate/ } \\
\text { great barrier } \\
\%\end{array}$ \\
\hline 1 & Statistical analyses are not understandable & 3.19 & & & & 78 \\
\hline 2 & Implications for practice are not made clear & 2.86 & & & & 71 \\
\hline 3 & $\begin{array}{l}\text { The amount of research information is } \\
\text { overwhelming }\end{array}$ & 2.75 & & & & 66 \\
\hline 4 & $\begin{array}{l}\text { The relevant literature is not compiled in one } \\
\text { place }\end{array}$ & 2.75 & & & & 65 \\
\hline 5 & $\begin{array}{l}\text { The research is not reported clearly and } \\
\text { readably }\end{array}$ & 2.73 & & & & 60 \\
\hline 6 & I do not have time to read research & & 2.63 & & & 54 \\
\hline 7 & Research is not readily available & 2.60 & & & & 55 \\
\hline 8 & The research is not relevant to my practice & 2.56 & & & & 59 \\
\hline 9 & I feel results are not generalizable to my setting & & 2.54 & & & 55 \\
\hline 10 & I am unaware of the research & & & & 2.54 & 55 \\
\hline 11 & $\begin{array}{l}\text { I do not feel capable of evaluating research } \\
\text { quality }\end{array}$ & & & & 2.51 & 62 \\
\hline 12 & Facilities are inadequate for implementation & & 2.50 & & & 53 \\
\hline 13 & $\begin{array}{l}\text { Medical staff will not cooperate with } \\
\text { implementation }\end{array}$ & & 2.50 & & & 53 \\
\hline 14 & $\begin{array}{l}\text { There is insufficient time on the job to } \\
\text { implement new ideas }\end{array}$ & & 2.40 & & & 43 \\
\hline 15 & The literature reports conflicting results & & & 2.35 & & 42 \\
\hline 16 & I am isolated from knowledgeable colleagues & & & & 2.30 & 41 \\
\hline 17 & $\begin{array}{l}\text { I am uncertain whether to believe research } \\
\text { results }\end{array}$ & & & 2.26 & & 42 \\
\hline 18 & The research has not been replicated & & & 2.24 & & 32 \\
\hline 19 & $\begin{array}{l}\text { Administrators/managers will not allow } \\
\text { implementation }\end{array}$ & & 2.24 & & & 41 \\
\hline 20 & $\begin{array}{l}\text { Other staff are not supportive of } \\
\text { implementation }\end{array}$ & & 2.22 & & & 40 \\
\hline 21 & The research has methodological inadequacies & & & 2.20 & & 38 \\
\hline 22 & $\begin{array}{l}\text { I feel benefits of changing practice will be } \\
\text { minimal }\end{array}$ & & & & 2.13 & 33 \\
\hline 23 & I do not feel I have enough authority to change & & 2.10 & & & 34 \\
\hline 24 & $\begin{array}{l}\text { Research reports/articles are not published fast } \\
\text { enough }\end{array}$ & & & 2.05 & & 36 \\
\hline 25 & $\begin{array}{l}\text { There is not a documented need to change } \\
\text { practice }\end{array}$ & & & & 1.98 & 35 \\
\hline 26 & $\begin{array}{l}\text { The conclusions drawn from the research are } \\
\text { not justified }\end{array}$ & & & 1.92 & & 21 \\
\hline 27 & I see little benefit for myself & & & & 1.81 & 23 \\
\hline 28 & I do not see the value of research for practice & & & & 1.51 & 12 \\
\hline \multirow[t]{2}{*}{29} & I am unwilling to change/try new ideas & & & & 1.48 & 12 \\
\hline & Total mean for factors & 2.78 & 2.39 & 2.17 & 2.03 & \\
\hline
\end{tabular}

aItem 3 does not belong to a specific factor but has been added here under communication. This does not affect the mean score. 
Characteristics of the Setting

Many allied health practitioners do not work in traditional organisations or in one single location. For this reason, this study uses the term "setting" instead of "organisation." Focus group participants raised issues of support, authority, and capacity. For example, lack of time was raised in all sessions. This was also a key theme for survey respondents.

\section{Characteristics of Research Evidence}

Focus group participants wanted more local research, done in a way they thought better reflected the people with whom they worked.

It is necessary to change policy but we need research done by grass roots - putting it out there so that people can get it. (Participant 3, Group 3)

Barriers Scale results for this factor did not show that the qualities of research were an impediment to research use. However, a number of comments mirrored the concerns voiced in the focus groups about the type of research being produced.

The stats are useful to plot social trends, but not for the micro-level I work at. We need a more human faced and centred scientific approach. (Survey Respondent 4)

\section{Characteristics of the Practitioner}

In terms of practitioners' views about research, two contrasting themes arose during the focus groups: a general appreciation of the need for research, and scepticism about the motivation behind some research.

Research is done just to say to the public that they are doing something. (Participant 2, Group 3)

Some saw it as the responsibility of policy makers rather than of frontline practitioners to implement findings.
I wouldn't have a whole lot of faith in research...It's great to have reports, but nothing getting done. (Participant 2, Group 1)

Not all practitioners felt capable of engaging in, or using, research. This view may come, in part, from how they saw their own role:

I think that people in the caring business don't have the scientific mindset and shy away from research. (Participant 3, Group 3)

In the survey, the lowest ranked Barriers Scale items were associated with the practitioner factor. The low mean scores for these items suggest that respondents did not dispute the value of research or see lack of personal willingness to use research as a significant barrier. The three highest rated practitioner items may be associated with having motivation but lacking the skills and resources to use research effectively. This is borne out by results from other parts of the survey (for example, high levels of current research use, and high demand for facilitators).

In light of the scepticism around research use raised in focus group discussions, the option "These skills are not relevant to my work" was added to the training preferences section of the survey. Thirteen percent $(n=9)$ chose this option. Although not obviously reflected in the Barriers Scale results, this view was further supported by survey comments.

A lot of expensive research produces results that many people know already. (Survey Respondent 45)

The direct and potentially critical nature of Barriers Scale practitioner items may make them unsuitable for measuring barriers associated with attitude and competence. Qualitative measures can give greater insight into these components. In this study, more cautious attitudes to research use were revealed in comments by some practitioners. 
Facilitators

One might reasonably assume that the resolution of barriers from every factor would facilitate research use. As part of the Barriers Scale, 46 respondents (65\%) proposed general facilitators. These items (roughly) mirrored barrier items, and once again emphasized research communication as the primary factor.

In the light of the focus group discussions and previous research (Bertulis \& Lord, 2005), survey respondents were also asked to rate a list of potential LIS facilitators, scoring from 1 ("not a facilitator") to 4 ("a great facilitator"). All options were rated as a moderate or a great facilitator by the majority of respondents who expressed an opinion (Table 3) (those who choose "no opinion" or did not respond, $6-8 \%$, were excluded from analysis).
Training

Enabling continuing education is consistent with Rogers's Diffusion of Innovations theory, that a knowledge stage is a prerequisite for research implementation. Research-related training has relevance to all four Barriers Scale factors. Survey respondents were asked to choose their preferred type, format and setting for training (Table 4, Figures 1 \& 2).

Respondents favoured practical workshops (44\%), though blended (24\%) and virtual (19\%) formats were also popular. Only two respondents (3\%) preferred one-to-one sessions, and only five ( $8 \%$ ) favoured having sessions in their own settings.

Table 3

Proposed Library and Information Service Facilitators

\begin{tabular}{lcc}
\hline & Mean Score & $\begin{array}{c}\text { Scored as moderate/great } \\
\text { facilitator (\%) }\end{array}$ \\
\hline A list of evidence based websites & 3.62 & 89.4 \\
An email newsletter summarising research news & 3.60 & 87.9 \\
"Plain English" summaries of new research & 3.54 & 91.0 \\
The facility to email an information professional & 3.28 & 81.8 \\
with a question & & 72.2 \\
Organised meetings with others from your field & 3.14 & 80.0 \\
Current awareness service & 3.09 & 67.7 \\
Help with literature searching & 3.03 & 53.0 \\
An online discussion forum with others from your & 2.79 & \\
area of practice & & \\
\hline
\end{tabular}

Note. For the open option "Other facilitator" no LIS suggestions were made.

Table 4

Preferred Type of Training on Understanding and Using Research

\begin{tabular}{lcc}
\hline Type of Training & No. & \% \\
\hline Advanced information-searching skills & 35 & 49.3 \\
Critical analysis of research & 32 & 45.1 \\
Research and evaluation methods & 23 & 32.4 \\
Basic information-searching skills & 14 & 19.7 \\
Basic computer skills (including email and Internet) & 4 & 5.6 \\
These skills are not relevant to my work & 9 & 12.7 \\
\hline
\end{tabular}

Note. For the open option "Other training" - one suggestion, "experiential training," was made.

Participants could choose more than one type of training 


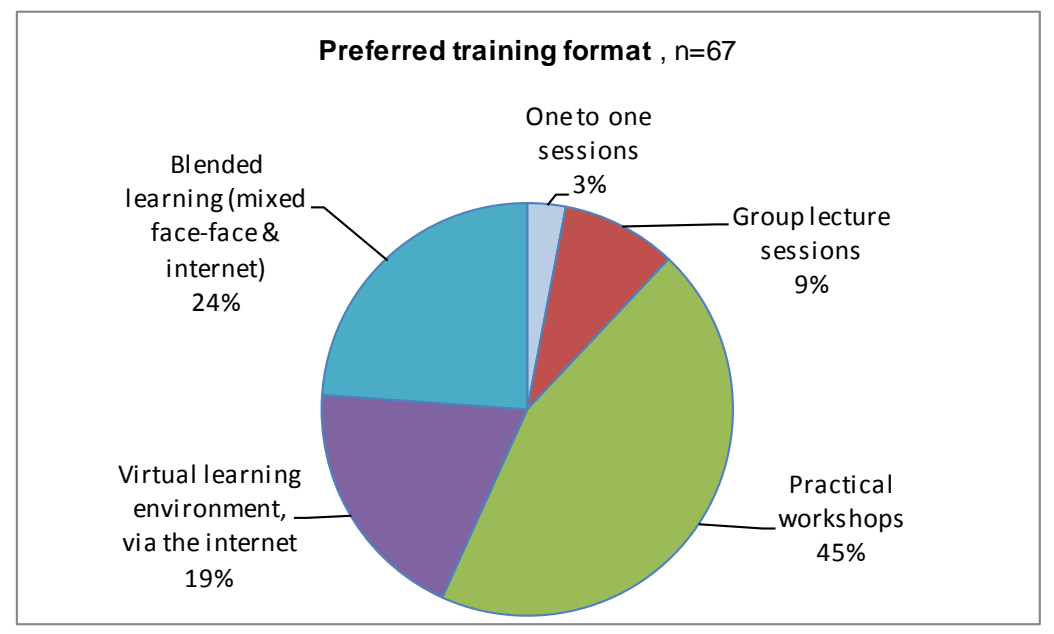

Figure 1

Preferred format for research-related training

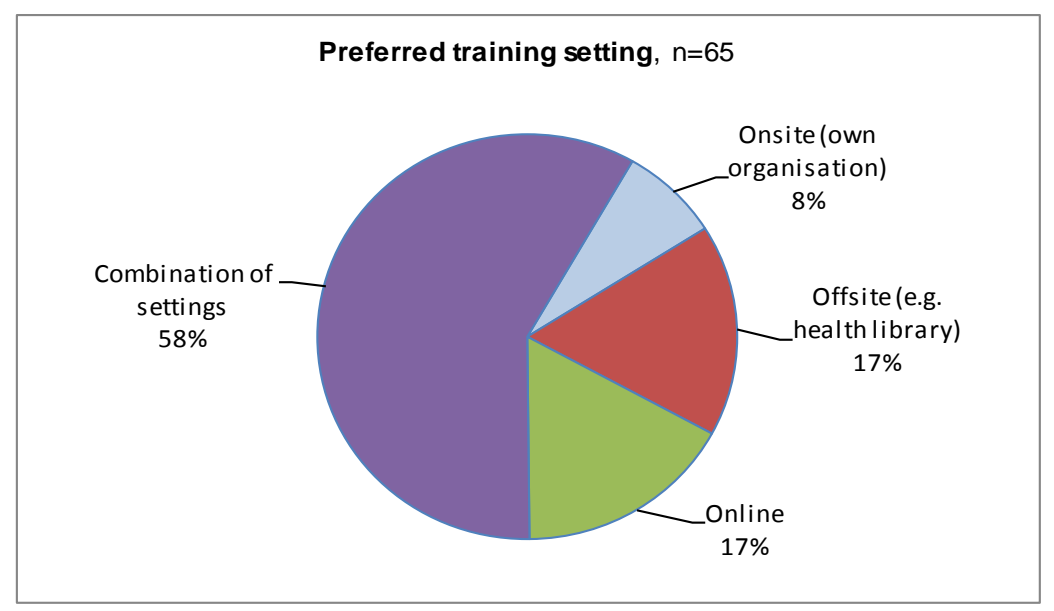

Figure 2

Preferred setting for research-related training

\section{Discussion}

The data collection methods used in this study revealed numerous issues to be addressed and ways to overcome them. The four-factor approach of the Barriers Scale provided a useful way of organizing themes from both focus groups and survey.

\section{Communication}

For the communication factor there was clear agreement between focus group and survey respondents. The prominence of this factor may be partly an artefact of the LIS focus of this study. However, it is likely that a diverse population without specified researchoriented qualifications or professional resource support systems do encounter these issues. This prominence provides both a challenge and opportunity for LIS in this area.

\section{Setting}

According to Rogers, organisational acceptance is a prerequisite to an individual's ability to adopt an innovation, and a system's norms can be a barrier to change (2003).

Focus on this factor is in line with recommendations from AOD literature that the scope of research transfer should be broader than training; it should also involve 
workforce development, so that change is accepted and reinforced at all levels in an organisation (Addiction Technology Transfer Center Network, 2004).

Barriers Scale scoring by nurses has shown remarkable consistency, with "insufficient time for nurses to implement new ideas" as the most frequently cited barrier in $73 \%$ of studies (Carlson \& Plonczynski, 2008). It is interesting to note that the item related to "lack of authority to change" has been rated as the greatest barrier in a number of studies (Glacken \& Chaney, 2004; Parahoo, 2000). Perhaps because counsellors have more clinical control than other practitioners, this item scored lowest of the "setting" barriers in the present study. This demonstrates that results cannot necessarily be transferred across client populations.

\section{Research Qualities}

In this study, survey items associated with the qualities of research received the second lowest total average score, indicating that participants generally trusted research methods and outputs. However, the comments made by focus group and survey respondents revealed that the type of research being conducted was often not relevant to practice.

Whereas other researchers have attributed "relevance" to the research factor (Osterling \& Austin, 2008), in the Barriers Scale relevance barriers are ascribed to the communication and setting factors. This might explain why, despite the reservations about research found in comments, there was a low barrier score for the research qualities factor.

\section{Practitioner}

According to Rogers (2003), the first step in the innovation-decision process is being aware of relevant research. But having sufficient information about what research does, its effects, and how to use it, is also a crucial early influence. Although a positive attitude alone is not necessarily sufficient to bring about the use of research, it has been found to influence and be a strong predictor of use in practice (Hutchinson \& Johnston, 2006).

The practitioner factor had the lowest average barrier score, though two items (being unaware of research and not capable of evaluation) were rated as moderate/great barriers by the majority of respondents. As in other studies, items related to personal motivation were rated at the bottom of the Barriers Scale (Glacken \& Chaney, 2004). There may be some bias in a question that asks practitioners whether their views or behaviour interfere with perceived competence, and comments suggested both positive and negative attitudes to literature-based research in this population.

Although most Barriers Scale items associated with practitioners were not rated as significant barriers, comments showed that some counsellors believed that treatment should stem almost exclusively from experience and evolving client need, rather than from literature-based research. Other studies have found social care cultures to be experiential rather than empirically based (Callaghan et al., 2008; Lewig et al., 2006).

\section{Training}

Careful planning is needed in order to offer learning opportunities and pathways that capture various skill levels, and to overcome geographical and temporal constraints.

For allied health practitioners, training that incorporates experiential learning is more likely to be effective (Skinner, Roche, Freeman \& McKinnon, 2009). Counsellors who feel isolated in work may not commit to using training interventions effectively (Joe, Broome, Simpson \& Rowan-Szal, 2007). Additional support and management "buy-in" may therefore be required. These factors must be built into needs and readiness assessments for the design of training programmes. 


\section{Study Limitations and Lessons Learned}

Although self-report data may not perfectly match reality, a mixed-method approach to data collection provided a rich source of information.

\section{Focus Groups}

Participating groups in this study were from a convenience sample, with attendance at the National Documentation Centre on Drug Use providing a valuable opportunity to obtain their views. Participants were from a rather specific cohort - those undertaking education - and may therefore have had an awareness of research that did not reflect that of the wider practitioner population. However, for these same reasons, they were likely to be key informants and provide important insights into this area.

\section{Survey}

In the absence of a national registry of allied health practitioners in Ireland, the best available source for one discipline (counsellors) was used as a sampling frame. This online directory was free, national, and up-to-date, but did not have complete coverage.

Counsellors were chosen because of their important frontline role and the lack of knowledge around their needs. However, the availability of a comprehensive contact listing was also a factor. One may surmise that the harder it is to locate other practitioners, the more they need to be located. Further research is required to carry out needs assessments with these hard-to-reach groups.

Engaging directly with health and community services should yield better access to practitioners for future studies. A partnership approach may also improve response rates, and identify the particular needs of client subgroups (such as those without Internet access or third-level qualifications).
Although care was taken to provide open options, social desirability bias (respondents answering in a way they think is expected) may have focused responses towards LISrelated issues. A key lesson was the importance of inviting comments. This option was used by 21 respondents $(30 \%)$ and provided insights that were not captured elsewhere.

Including a validated standard measurement instrument in the survey design is time-saving and provides a strong basis for enquiry and comparison. However, it also imposes restrictions in terms of content, language, and length. The Barriers Scale is quite long and, even though some adaptations were made, the language remained difficult to interpret in places. Although creation and testing of a new tool was beyond the scope of this study, a simpler, plain language, facilitator based scale would be preferable for future studies. Indepth qualitative methods, such as interview, would provide greater insight into practitioner and research factor elements.

\section{Conclusion}

In order to ensure that research resources are used effectively, LIS personnel should understand potential barriers to use, and develop services and strategies to address these issues. A mixed-method approach to data collection offers the broad scope required to capture the numerous issues involved in research use in practice. Quantitative methods offer large-scale feedback. Qualitative assessment methods reveal insight into personal attitudes and concerns.

The barriers and facilitators to research use identified in this study could be placed within four interactive and overlapping factors: communication, setting, research, and practitioner. The importance of communication barriers in particular, and the enthusiasm shown for facilitators in this study, suggest that library and information services have a key role to play in making 
research resources more compatible with practitioner need. It is hoped that these findings will assist LIS personnel to ascertain and understand the issues that clients face in accessing and making use of their resources.

\section{Acknowledgements}

For their support and guidance, I would like to thank my colleagues Brian Galvin, Louise Farragher, and Mariea Nelson in the National Documentation Centre on Drug Use. I would also like to thank Hugh Preston from Aberystwyth University for his astute and helpful comments.

Finally, and most importantly, I would like to express my gratitude to all participants, whose valuable opinions and insight formed the core of this study. It is my hope that these contributions will have an impact on the way library and information services are provided to allied health practitioners in the future.

Initial results from this paper were presented in the form of a poster at the $6^{\text {th }}$ International Evidence Based Library and Information Practice Conference, Salford, UK, June 2011. The poster won the audience nominated "best poster" award.

\section{References}

Arney, F. M., Bromfield, L. M., Lewig, K., \& Holzer, P. (2009). Integrating strategies for delivering evidenceinformed practice. Evidence \& Policy, 5(2), 179-91. doi:10.1332/174426409X437928

Addiction Technology Transfer Center (ATTC) Network Technology Transfer Workgroup. (2011). Research to practice in addiction treatment: key terms and a field-driven model of technology transfer. Journal of Substance Abuse Treatment, 41(2), 169178. doi:10.1016/j.jsat.2011.02.006
Addiction Technology Transfer Center Network (2004). The change book: a blueprint for technology transfer $\left(2^{\text {nd }}\right.$ ed.). In Addiction Technology Transfer Center Network. Retrieved 16 Nov. 2011 from http://www.nattc.org/pdf/The_Chang e_Book_2nd_Edition.pdf

Bandura, A. (1994). Self-efficacy. In V. S. Ramachaudran (Ed.), Encyclopedia of human behavior (Vol. 4, pp. 71-81). New York: Academic Press. (Reprinted in Friedman H. (Ed.), (1998). Encyclopedia of mental health. San Diego: Academic Press). Retrieved 16 Nov. 2011 from http://des.emory.edu/mfp/BanEncy.ht $\mathrm{ml}$

Bartholomew, N. G., Joe, G. W., Rowan-Szal, G. A., \& Simpson, D. D. (2007). Counselor assessments of training and adoption barriers. Journal of Substance Abuse Treatment, 33(2), 193-199. doi:10.1016/j.jsat.2007.01.005

Bertulis, R., \& Lord, J. (2005). Report of key findings of RCN's survey of the information needs of nurses, health care assistants, midwives and health visitors. In Royal College of Nursing. Retrieved 16 Nov. 2011 from http://www.rcn.org.uk/_data/assets/p df_file/0014/112082/003216.pdf

Booth, A. (2003). Bridging the researchpractice gap? The role of evidence based librarianship. New Review of Information and Library Research, 9(1), 3-23.

doi:10.1080/13614550410001687909

Boström, A.-M., Kajermo, K. N., Nordström, G., \& Wallin, L. (2008). Barriers to research utilization and research use among registered nurses working in the care of older people: does the BARRIERS Scale discriminate between research users and non-research users on perceptions of barriers? 
Implementation Science, 2008, 3(24). doi:10.1186/1748-5908-3-24

Bywood, P., Lunnay, B., \& Roche, A. (2008a). Effective dissemination: a systematic review of implementation strategies for the AOD field. In National Centre for Education and Training on Addiction. Retrieved 16 Nov. 2011 from http://nceta.flinders.edu.au/download _file/-/view/378

Bywood, P. T., Lunnay, B., \& Roche, A. M. (2008b). Effective dissemination: an examination of theories and models of change for research dissemination in the AOD field. In National Centre for Education and Training on Addiction. Retrieved 16 Nov. 2011 from http://nceta.flinders.edu.au/download _file/-/view/385

Callaghan, L., Doherty, A., Lea, S. J., \& Webster, D. (2008). Understanding the information and resource needs of UK health and social care placement students. Health Information and Libraries Journal, 25(4), 253-260. doi:10.1111/j.1471-1842.2008.00769.x

Carlson, C. L., \& Plonczynski, D. J. (2008). Has the BARRIERS Scale changed nursing practice? An integrative review. Journal of Advanced Nursing, 63(4), 322333. doi:10.1111/j.13652648.2008.04705.x

Closs, S. J., \& Bryar, R. M. (2001). The BARRIERS Scale: does it 'fit' the current NHS research culture? Journal of Research in Nursing; 6(5), 853-865. doi:10.1177/136140960100600509

Cochrane, L. J., Olson, C. A., Murray, S., Dupuis, M., Tooman, T., \& Hayes, S. (2007). Gaps between knowing and doing: understanding and assessing the barriers to optimal health gain. Journal of Continuing Education in the Health-Professions, 27(2), 94-102. doi:10.1002/chp.106
Eccles, C. (2009). Effective delivery of evidence-informed practice. Evidence E Policy, 5(2), 193-206. doi:10.1332/174426409X437937

Frasure, J. (2008). Analysis of instruments measuring nurses' attitudes towards research utilization: a systematic review. Journal of Advanced Nursing, 61(1), 5-18. doi:10.1111/j.13652648.2007.04525.x

Funk, S. G., Champagne, M. T., Wiese, R. A., \& Tornquist, E. M. (1991). BARRIERS: The barriers to research utilization scale. Applied Nursing Research, 4(1), 39-45. Retrieved 16 Nov. 2011 from http://www.sciencedirect.com/science ?_ob=MiamilmageURL\&_cid=272378 \&_user $=1069227 \& \_p i i=S 089718970580$ 0527\&_check=y\&_origin=browse\&_zo ne=rslt_list_item\&_coverDate $=1991$ 02-28\&wchp $=$ dGLzVlkzSkWz\&md5=059f32cdf665ad8ab4a6e 2bc96163583/1-s2.0S0897189705800527-main.pdf

Gioia, D. (2007). Using an organizational change model to qualitatively understand practitioner adoption of evidence-based practice in community mental health. Best Practices in Mental Health, 3(1), 1-15.

Glacken, M., \& Chaney, D. (2004). Perceived barriers and facilitators to implementing research findings in the Irish practice setting. Journal of Clinical Nursing, 13(6), 731-740. doi:10.1111/j.1365-2702.2004.00941.x

Greenhalgh, T., Robert, G., Macfarlane, F., Bate, P., \& Kyriakidou, O. (2004). Diffusion of innovations in service organizations: systematic review and recommendations. The Milbank Quarterly, 82(4), 581-629. Retrieved 16 Nov. 2011 from http://www.milbank.org/quarterly/820 4feat.html 
Helfrich, C. D., Li Y.-F., Sharp, N. D., \& Sales, A. E. (2009). Organizational readiness to change assessment (ORCA): development of an instrument based on the Promoting Action on Research in Health Services (PARIHS) framework. Implementation Science, 4(38). doi:10.1186/1748-5908-4-38

Hutchinson, A. M., \& Johnston, L. (2004). Bridging the divide: a survey of nurses' opinions regarding barriers to, and facilitators of, research utilization in the practice setting. Journal of Clinical Nursing, 13(3), 304-315. doi: 10.1046/j.1365-2702.2003.00865.x

Hutchinson, A. M., \& Johnston, L. (2006). Beyond the BARRIERS Scale: commonly reported barriers to research use. Journal of Nursing Administration, 36(4), 189-199. Retrieved 16 Nov. 2011 from http://journals.lww.com/jonajournal/A bstract/2006/04000/Beyond_the_BARR IERS_Scale_Commonly_Reported.8.a spx

Joe, G. W., Broome, K. M., Simpson, D. D., \& Rowan-Szal, G. A. (2007). Counselor perceptions of organizational factors and innovations training experiences. Journal of Substance Abuse Treatment, 33(2), 171-182. doi:10.1016/j.jsat.2006.12.027

Kitson, A. L., Rycroft-Malone, J., Harvey, G., McCormack, B., Seers, K., \& Titchen, A. (2008). Evaluating the successful implementation of evidence into practice using the PARiHS framework: theoretical and practical challenges. Implementation Science, 3(1). doi:10.1186/1748-5908-3-1

Lewig, K. Arney, F., \& Scott, D. (2006). Closing the research-policy and researchpractice gaps: ideas for child and family services. Family Matters, 74, 1219. Retrieved 16 Nov. 2011 from http://www.aifs.gov.au/institute/pubs/ fm2006/fm74/kl.pdf

Marshall, J. G. (2007). Measuring the value and impact of health library and information services: past reflections, future possibilities. Health Information and Libraries Journal, 24(Supp. 1), 4-17. doi:10.1111/j.1471-1842.2007.00750.x

McCormack, B., McCarthy, G., Wright, J., Slater, P., \& Coffey, A. (2009). Development and testing of the Context Assessment Index (CAI). Worldviews on Evidence-Based Nursing, 6(1), 27-35. doi:10.1111/j.17416787.2008.00130.x

McMaster, T., \& Wastell, D. (2005). Diffusion or delusion? Challenging an IS research tradition. Information Technology E People; 18(4), 383-404. doi:10.1108/09593840510633851

Kajermo, K. N., Boströlm, A.-M., Thompson, D. S., Hutchinson, A. M., Estabrooks C. A., \& Wallin, L. (2010). The BARRIERS scale -- the barriers to research utilization scale: a systematic review. Implementation Science, 5(32). doi:10.1186/1748-5908-5-32

Osterling, K. L., \& Austin, M. J. (2008). The dissemination and utilization of research for promoting evidencebased practice, Journal of EvidenceBased Social Work, 5(1/2), 295-319. doi:10.1300/J394v05n01_11

Parahoo, K. (2000). Barriers to, and facilitators of, research utilization among nurses in Northern Ireland. Journal of Advanced Nursing, 31(1), 89-98. doi:10.1046/j.1365-2648.2000.01256.x

Retsas, A. (2000). Barriers to using research evidence in nursing practice. Journal of Advanced Nursing, 31(3), 599-606. doi:10.1046/j.1365-2648.2000.01315.x 
Rogers, E. M. (1962). Diffusion of innovations. Illinois: Free Press of Glencoe.

Rogers, E. M. (2003). Diffusion of innovations. ( $5^{\text {th }}$ ed.). New York: Free Press.

Simpson, D. D., \& Flynn, P. M. (2007). Moving innovations into treatment: a stagebased approach to program change. Journal of Substance Abuse Treatment, 33(2), 111-120. doi:

10.1016/j.jsat.2006.12.023

Skinner, N., Roche, A. M., Freeman, T., \& McKinnon, A. (2009). Health professionals' attitudes towards AODrelated work: Moving the traditional focus from education and training to organizational culture, Drugs:

Education, Prevention and Policy, 16(3), 232-249.

doi:10.1080/09687630902876338
Walter, I., Nutley, S., Percy-Smith, J., McNeish, D., \& Frost, S. (2004). Improving the use of research in social care practice. In Social Care Institute for Excellence. Retrieved 16 Nov. 2011 from http://www.scie.org.uk/publications/k nowledgereviews/kr07.pdf

Yava, A., Tosun, N., Çiçek, H., Yavan, T., Terakye, G., \& Hatipoğlu, S. (2009). Nurses' perceptions of the barriers to and the facilitators of research utilization in Turkey. Applied Nursing Research, 22(3), 166-175. doi:10.1016/j.apnr.2007.11.003 